\title{
Optimization of adsorption of cationic dye from aqueous solution by biochar from artichoke waste using response surface methodology
}

\author{
Fatima Ouzidan*, Nadia Amardo, Mhammed el kouali and Mohammed Talbi \\ Laboratory of Analytical Chemistry and Physico-Chemistry of Materials, Department of Chemistry, \\ Faculty of sciences Ben M'sik, University Hassan II of Casablanca, Morocco
}

\begin{abstract}
The use of experimental design and in particular the response surface methodology (RSM) allowed the determination of the influence of the simultaneous effects and the interaction of the operating parameters on the methylene blue removal efficiency. The parameters studied were the initial concentration of the adsorbate, the stirring speed, mass and particle size of the adsorbent. The results show that the application of RSM allows describing the influence of these four experimental parameters on the treatment effectiveness. The second-order model obtained, for the Methylene Blue (MB) removal efficiency was validated by using different statistical approaches. The use of the ANOVA showed that the model is significant and in functional adequacy with the experimental results.
\end{abstract}

Keywords: Adsorption, Experimental design, response surface methodology RSM, ANOVA.

\section{Introduction}

The discharges of the effluent colored in nature are not only unpleasant for the environment but also affects a lot of biological cycles. These discharges present a real danger to humankind and the environment by cause of their poor biodegradability ${ }^{1-9}$. Several treatments have been used to reduce the harmful effects of effluent discharge ${ }^{10}$. One of the most used techniques in water purification discharges of these industries is adsorption, which is a technique of low cost compared to other methods used in the bleaching process ${ }^{11-18}$.

The design of experiments methodology (DEP) is a strategy for planning scientific and industrial experiments to remove information corresponding to the objective that has been previously set. The analysis of the information collected uses statistical methods ${ }^{19-21}$.

It can be applied to many disciplines and industries as long as we search for the correlation between a quantity of interest $(\mathrm{Y})$ and variables $\left(\mathrm{X}_{\mathrm{i}}\right)^{22}$. In this method, the response can be written as follows:

$Y=f\left(X_{1}, X_{2}, X_{3}, \ldots \ldots \ldots \ldots \ldots, X_{k}\right)+\varepsilon$

Where $\mathrm{f}$ is the response function that depends on random variables $\mathrm{X}_{\mathrm{i}}$; $\varepsilon$ is a term that represents other sources of variability.

This work consists of optimizing the removal of $\mathrm{MB}$ dye by adsorption. The influence of the pollutant concentration, the stirring speed, mass and particle size of the adsorbent was also studied using the response surface methodology. This method allows, through empirical mathematical models to determine an approximate relationship between the output response and the input variables to optimize the process parameters in order to achieve a desirable response ${ }^{23-28}$.

The advantages of this method are:

a decrease in the number of tests,

a higher number of factors studied,

a determination of the interactions between factors, a better precision on the results ${ }^{29}$.

\section{Materials and methods}

\subsection{Adsorbent}

The adsorbent used in this work is artichoke waste, which was washed, then dried in an oven at $100^{\circ} \mathrm{C}$ for 24 hours. It was crushed, then carbonized at $650^{\circ} \mathrm{C}$ for one and a half hours.

The material used as an adsorbent in this study is the biochar, which can be obtained from the artichoke waste $^{30}$.

\subsection{Adsorbate}

The dye we used is methylene blue (Table 1). The concentration 
of the dye solution MB was determined using a UV-vis spectrophotometer (Shimadzu UV-mini spectrometry 1240) in maximal wavelength of 664 $\mathrm{nm}$. The percentage removal of the contaminant was calculated by the following equation ${ }^{31}$ :
$\mathrm{R}(\%)=\frac{\mathrm{C}_{0}-\mathrm{C}_{\mathrm{e}}}{\mathrm{C}_{0}} * 100$

Where $\mathrm{C}_{0}$ and $\mathrm{C}_{\mathrm{e}}$ are respectively, the initial and equilibrium concentrations of dye $\left(\mathrm{mg} \mathrm{l}^{-1}\right)$.

Table 1. Methylene blue characteristics.

\begin{tabular}{|c|c|c|}
\hline & Chemical formula & $\mathrm{C}_{16} \mathrm{H}_{18} \mathrm{~N}_{3} \mathrm{~S}^{+} \mathrm{Cl}^{-}$ \\
\hline
\end{tabular}

\subsection{Mathematical model}

The behavior of the response surface was explained bya full second-order polynomial model, as shown in

the following equation ${ }^{28,32-35}$.

$$
\begin{gathered}
Y=\beta_{0}+ \\
\sum_{i=1}^{n} \beta_{i} X_{i} \sum_{i=1}^{n} \beta_{i i} X_{i}^{2}+\sum \sum_{i=1 \quad j=1}^{n} \beta_{i j} X_{i} X_{j}
\end{gathered}
$$

(3)

This type of model can estimate a response surface to study the linear effects, quadratic effects and interaction effects:

- $\quad \mathrm{Y}$ is the response function.

- $\quad \beta_{0}$ is the constant polynomial that expresses the general average effect.

- $\quad \beta_{\mathrm{i}}, \beta_{\mathrm{ii}}, \beta_{\mathrm{ij}}$ are the coefficients of the linear effect, quadratic and interaction, respectively.

- $X_{i}$ and $X_{j}$ represent the independent coded variables.
The NEMRODW ${ }^{36}$ software was used to determine the polynomial coefficients for the response. The degree of significance of the coefficients was determined using the test student. Verification of the fitted model was performed by the regression coefficient $\left(\mathrm{R}^{2}\right)$.

\subsection{Matrix experience and experimental field}

We chose a central composite design in a cubic field allowing 3 levels of factor which are (-1), (0) and (1) as shown in Table 2. The experience of the number of central plans is determined using the following equation (4). According to this equation ${ }^{33}$, the total number of tests to be performed for $\mathrm{k}=4$ and $\mathrm{n}_{0}=2$, is of 27 tests. The results are summarized in Table 3.

$N=2^{K}+2 K+n_{0}$

Where $\mathrm{k}$ is the number of input factors. And $\mathrm{n}_{0}$ the number of field tests in the center.

Table 2. Experimental field.

\begin{tabular}{|c|c|c|c|}
\hline Factors & Level (-1) & Level (0) & Level (1) \\
\hline Concentration of dye $\left(\mathbf{m g ~ l}^{\mathbf{1}}\right)\left(\mathbf{X}_{\mathbf{1}}\right)$ & 10 & 20 & 30 \\
\hline Mass $(\mathrm{mg})\left(\mathbf{X}_{2}\right)$ & 90 & 107.5 & 125 \\
\hline particle size $(\mathrm{mm})\left(\mathbf{X}_{3}\right)$ & 0.08 & 0.115 & 0.15 \\
\hline stirring speed $(\mathrm{rpm})\left(\mathrm{X}_{4}\right)$ & 800 & 1200 & 1600 \\
\hline
\end{tabular}

Table 3. Matrix of tests and experimental response.

\begin{tabular}{|c|c|c|c|c|c|}
\hline $\mathbf{N}^{\circ} \mathbf{E x p}$ & $\mathbf{X}_{\mathbf{1}}\left(\mathbf{m} \mathbf{g} \mathbf{~}^{-\mathbf{1}}\right)$ & $\mathbf{X}_{\mathbf{2}}(\mathbf{m g})$ & $\mathbf{X}_{\mathbf{3}}(\mathbf{m m})$ & $\mathbf{X}_{\mathbf{4}}(\mathbf{r p m})$ & $\mathbf{Y}(\mathbf{\%})$ \\
\hline $\mathbf{1}$ & -1 & -1 & -1 & -1 & 72.76 \\
\hline $\mathbf{2}$ & 1 & -1 & -1 & -1 & 54.50 \\
\hline $\mathbf{3}$ & -1 & 1 & -1 & -1 & 79.32 \\
\hline $\mathbf{4}$ & 1 & 1 & -1 & -1 & 54.22 \\
\hline $\mathbf{5}$ & -1 & -1 & 1 & -1 & 36.23 \\
\hline $\mathbf{6}$ & 1 & -1 & 1 & -1 & 51.61 \\
\hline $\mathbf{7}$ & -1 & 1 & 1 & -1 & 42.77 \\
\hline $\mathbf{8}$ & 1 & 1 & 1 & -1 & 51.96 \\
\hline
\end{tabular}




\begin{tabular}{|c|c|c|c|c|c|}
\hline 9 & -1 & -1 & -1 & 1 & 62.90 \\
\hline 10 & 1 & -1 & -1 & 1 & 53.63 \\
\hline 11 & -1 & 1 & -1 & 1 & 75.31 \\
\hline 12 & 1 & 1 & -1 & 1 & 49.32 \\
\hline 13 & -1 & -1 & 1 & 1 & 30.90 \\
\hline 14 & 1 & -1 & 1 & 1 & 52.31 \\
\hline 15 & -1 & 1 & 1 & 1 & 49.82 \\
\hline 16 & 1 & 1 & 1 & 1 & 53.32 \\
\hline 17 & -1 & 0 & 0 & 0 & 56.38 \\
\hline 18 & 1 & 0 & 0 & 0 & 53.54 \\
\hline 19 & 0 & -1 & 0 & 0 & 40.74 \\
\hline 20 & 0 & 1 & 0 & 0 & 47.03 \\
\hline 21 & 0 & 0 & -1 & 0 & 49.19 \\
\hline 22 & 0 & 0 & 1 & 0 & 38.50 \\
\hline 23 & 0 & 0 & 0 & -1 & 44.41 \\
\hline 24 & 0 & 0 & 0 & 1 & 44.27 \\
\hline 25 & 0 & 0 & 0 & 0 & 41.13 \\
\hline 26 & 0 & 0 & 0 & 0 & 37.31 \\
\hline 27 & 0 & 0 & 0 & 0 & 39.64 \\
\hline
\end{tabular}

\section{Results and Discussion}

\subsection{Statistical analysis of the results}

In order to determine the quality description of the model and to know if the model is correct, it is necessary to realize the statistical analysis of the model in its totality. A variance analysis Table 4 (ANOVA) is constructed using the statistical test of Fisher ${ }^{37,38}$. The analysis of variance is to explain the total variation of the response which decomposes into a sum of squares of the variation due to the regression and a sum of squares differences or residuals ${ }^{31,39}$. The quality of the adjustment of the model was verified by the coefficient of determination $\left(R^{2}\right)^{34}$. In this case, the value of the coefficient of determination $\left(\mathrm{R}^{2}=0.9697\right)$ indicates that only $2.06 \%$ of the total variations are not explained by the model. The value of the adjusted coefficient of determination $\left(\mathrm{R}^{2}\right.$ adj $=$ 0.9344 ) is also very high, indicating a high significance of the model, using the statistical test of Fisher.

Table 4. ANOVA Results.

\begin{tabular}{|c|c|c|c|c|c|}
\hline $\begin{array}{c}\text { Source of } \\
\text { variation }\end{array}$ & $\begin{array}{c}\text { Sum of } \\
\text { squares }\end{array}$ & $\begin{array}{c}\text { degree of } \\
\text { freedom }\end{array}$ & mean square & Fc & Fcritique \\
\hline Régression & 3467.9866 & 14 & 247,713 & $\mathrm{Fc}=27.493$ & 2.64 \\
\hline Résidus & 108.12224 & 12 & 9.010 & & \\
\hline Total & 3576.373 & 26 & & \\
\hline
\end{tabular}

\subsection{Statistical analysis of the coefficients of the model}

The purpose of this statistical test is to know if there are coefficients that are not influential, that is to say, which do not affect each response. The estimated values of the coefficients of the model and the significance are given in Table 4.
Analysis of the results shows that the concentration $\left(\mathrm{X}_{1}\right)$, particle size $\left(\mathrm{X}_{3}\right)$ and the stirring speed $\left(\mathrm{X}_{4}\right)$ have a negative influence. Indeed, the minimum value of these factors results in a higher response. $\mathrm{X}_{2}$ factor (the mass of adsorbent) has a positive sign indicating that the maximum value of this factor results in a higher response.

Table 5. Analysis table coefficients

\begin{tabular}{|c|c|c|c|c|}
\hline Nam & C_aff: & Standard & t.exp. & Signif. \\
\hline
\end{tabular}




\begin{tabular}{|r|r|r|r|r|}
\hline b0 & 42.228 & 1.106 & 38.1 & $<0.01$ \\
\hline b1 & -1.777 & 0.708 & -2.51 & $2.63 *$ \\
\hline b2 & 2.638 & 0.708 & 3.73 & $0.291 * *$ \\
\hline b3 & -7.985 & 0.708 & - & $<0.01$ \\
\hline b4 & -0.889 & 0.708 & -1.26 & 23.2 \\
\hline b11 & 11.298 & 1.872 & 6.04 & $\begin{array}{c}\text { *** } \\
\text { *** }\end{array}$ \\
\hline b22 & 0.223 & 1.872 & 0.12 & 90.3 \\
\hline b33 & 0.183 & 1.872 & 0.10 & 92.1 \\
\hline
\end{tabular}

\begin{tabular}{|c|c|c|c|c|}
\hline b44 & 0.678 & 1.872 & 0.36 & 72.3 \\
\hline b12 & -2.979 & 0.750 & -3.97 & $0.192 * *$ \\
\hline b13 & 8.006 & 0.750 & 10.6 & $<0.01$ \\
\hline b23 & 0.778 & 0.750 & 1.04 & 32.2 \\
\hline b14 & 0.528 & 0.750 & 0.70 & 50.2 \\
\hline b24 & 0.929 & 0.750 & 1.24 & 23.8 \\
\hline b34 & 1.464 & 0.750 & 1.95 & 7.2 \\
\hline
\end{tabular}

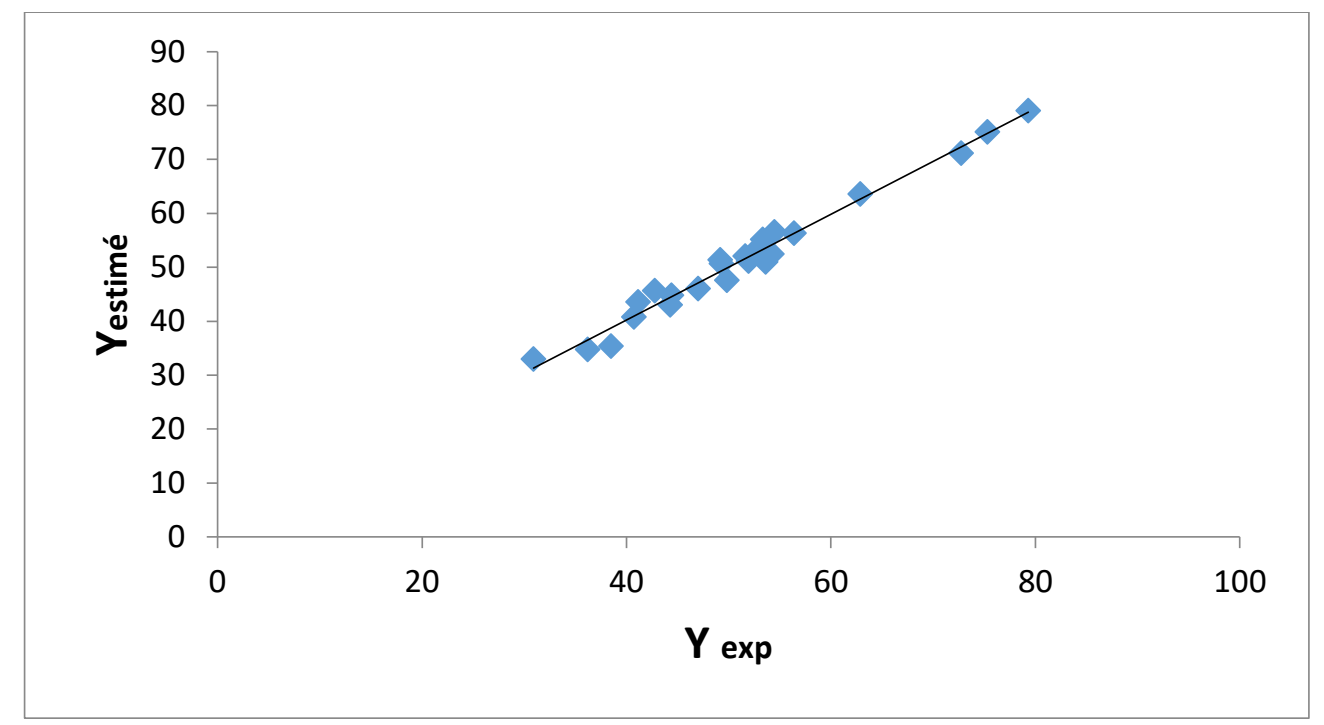

Figure 1. Estimated Response in the experimental response

The Figure 1 shows that there is a good correlation between the experimental values and the estimated values because they are very close to the straight line.

\subsection{Graphical analysis of the results}

The experimental field being defined from the variation of two factors. The graphic analysis and more particularly, the response surfaces for studying

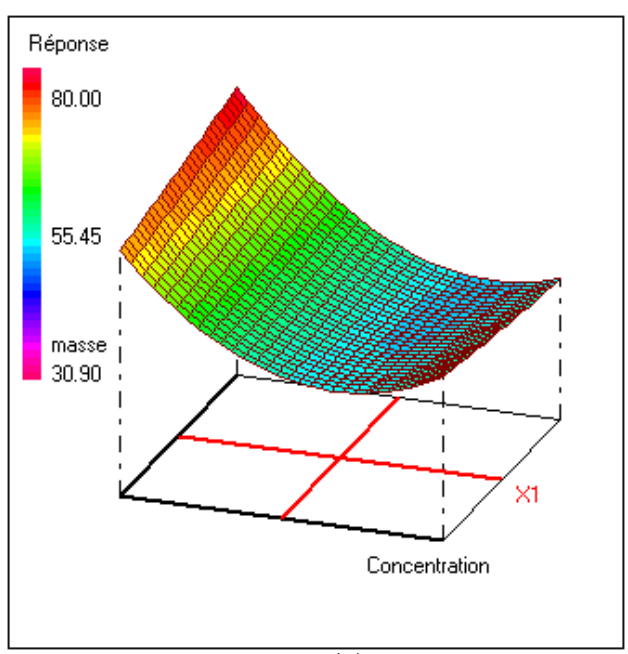

(a) the behavior responses depending on input parameters.

Figures 2 to 6 represent the response surface of threedimensional, which was constructed to show the effects of the parameters on the removal efficiency of methylene blue.

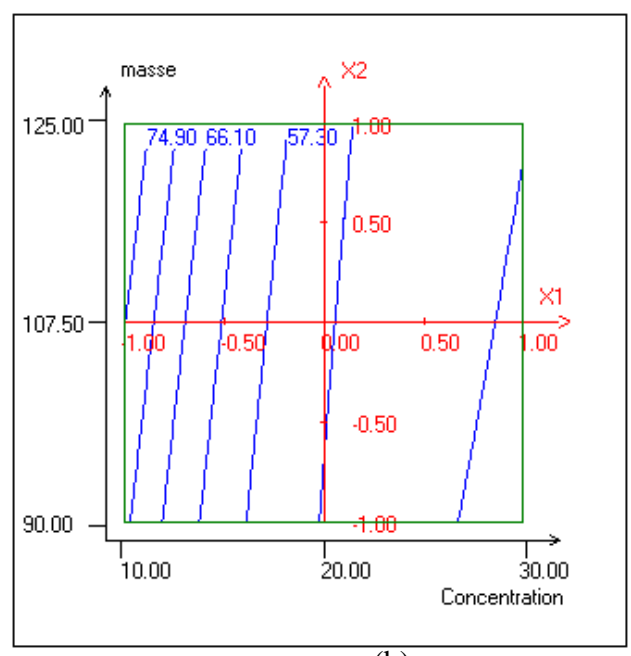

(b)

Figure 2. Representation of the response in the plan: Concentration vs masse (a:3D et b:2D) 


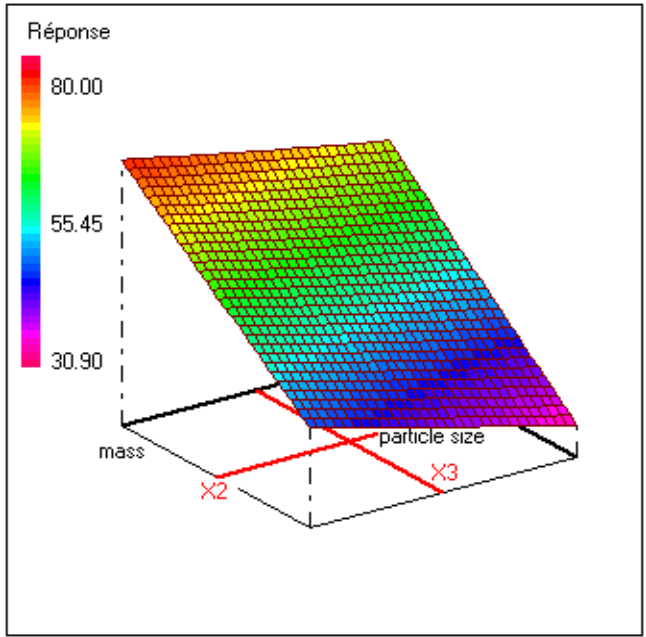

(a)

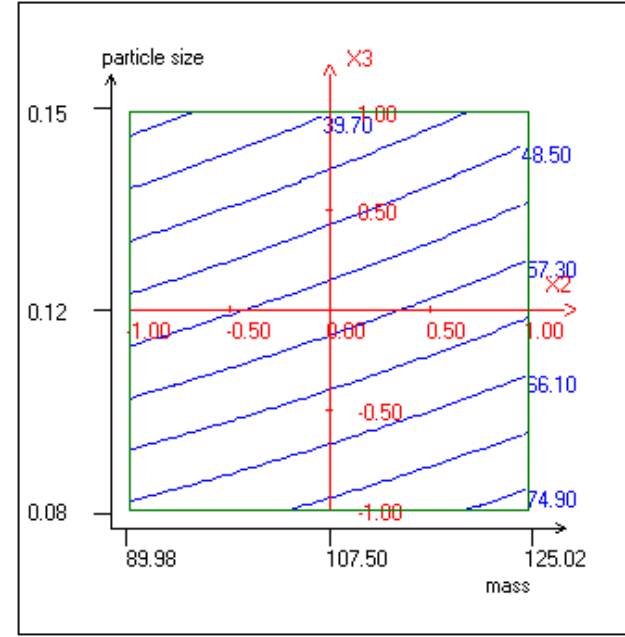

(b)

Figure 3. Representation of the response in the plan: Masse vs particle size (a:3D et b:2D)

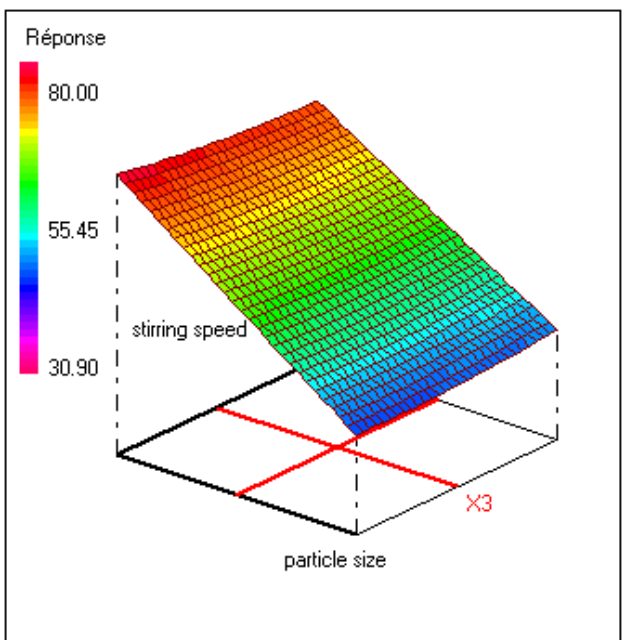

(a)

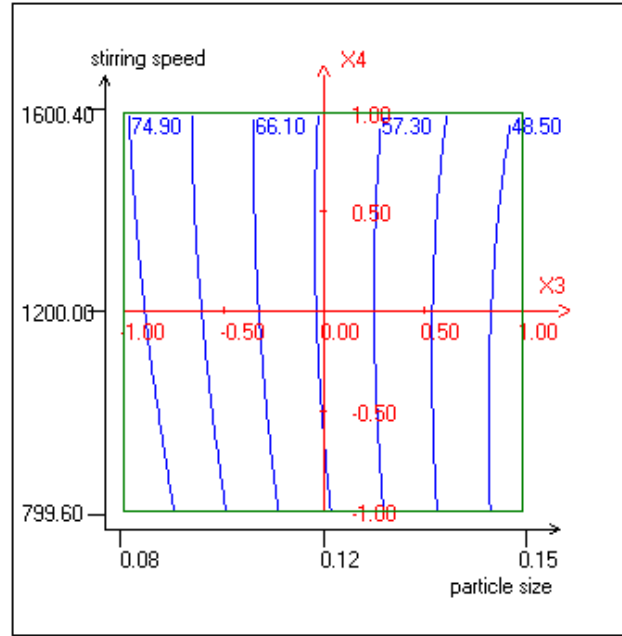

(b)

Figure 4. Representation of the response in the plan: particle size vs stirring speed (a:3D et b:2D).

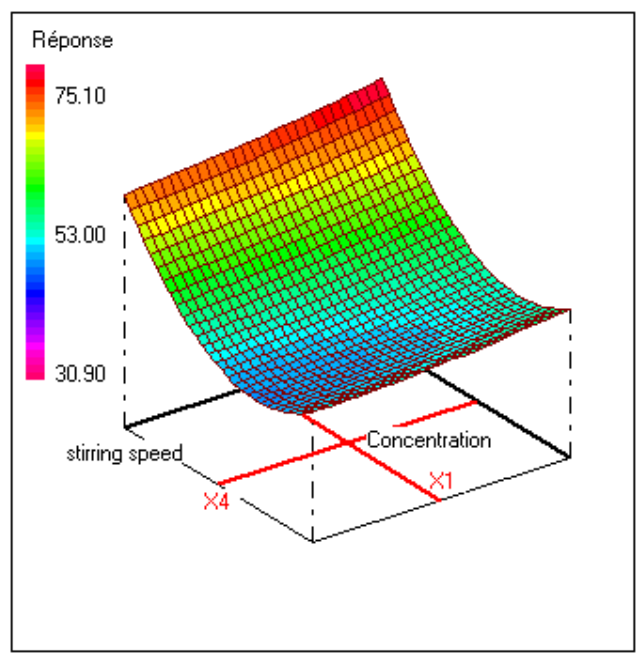

(a)

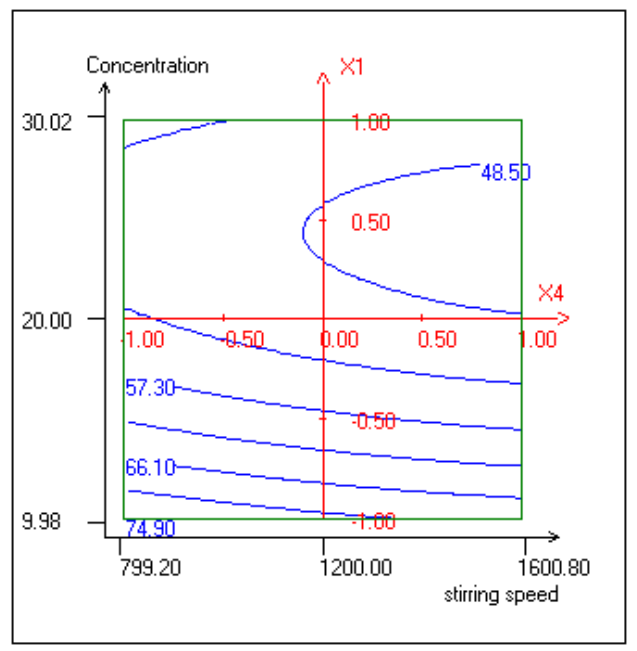

(b)

Figure 5. Representation of the response in the plan: stirring speed vs Concentration 


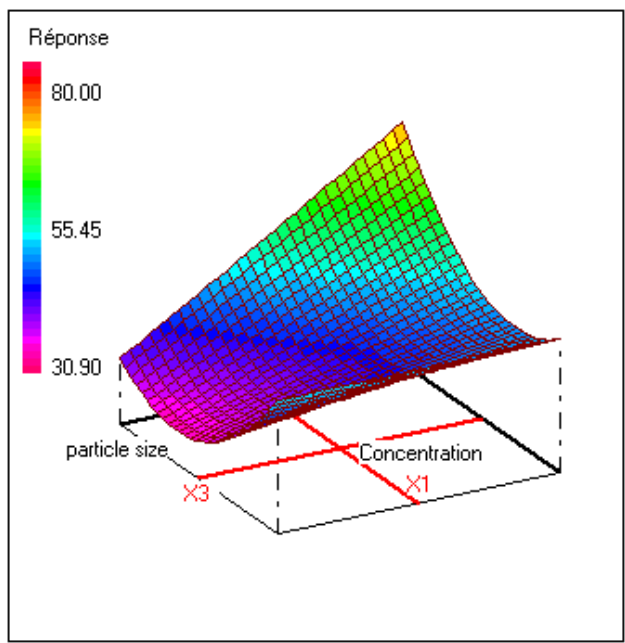

(a)

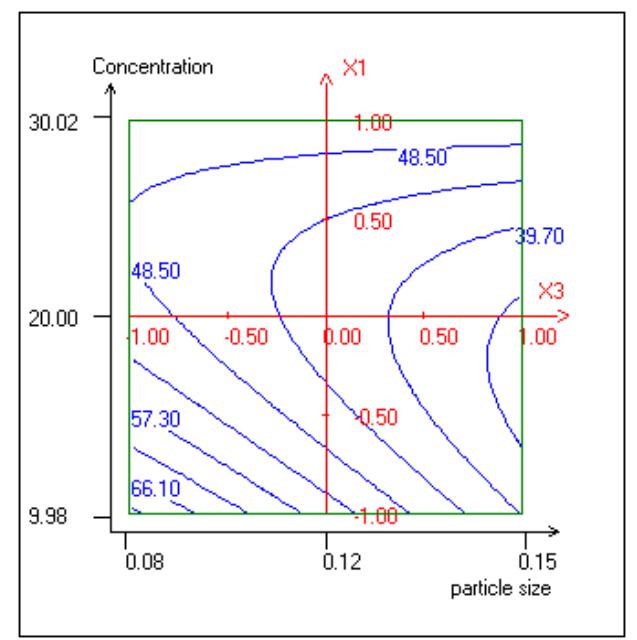

(b)

Figure 6. Representation of the response in the plan: Concentration vs particle size (a:3D et b:2D)

Figures 2-6 represent the response surface of three dimensions which was constructed to show the effects of the parameters on the removal efficiency of methylene blue. Figure 2 shows the effect of mass and concentration of adsorbate on the decolorization efficiency, the influence of these variables on the dye removal efficiency was significant for low values of dye concentration and higher values of the amount of adsorbent. Figure 3 shows the effect of particle size and mass of adsorbent. A decrease in particle size leads to a significant increase in the elimination of the dye, while an increase in the mass of adsorbent gives the same result. The effect of the stirring rate and particle size on the response is shown in Figure 4. The yield was increased with decreasing particle size and increases slightly with low stirring speed. The results illustrated in Figure 5 shows that the concentration has a significant effect on the elimination of methylene blue. The yield increases slightly with decreasing the stirring speed. Figure 6 shows the effect of particle size and concentration of adsorbate. The decolorization efficiency increased with a decrease in the two variables studied.

\section{Conclusion}

To study the effect of the independent variables: the concentration of dye, stirring speed, mass and particle size of adsorbent on the elimination of methylene blue, we modeled the response as a polynomial function of these parameters. The results show that the application of response surface methodology and the central composite design are used to describe and model a correct manner the influence of these four experimental parameters on the efficacy of treatment. The reliability of the modelbased second order was tested by the analysis method (ANOVA). This analysis showed that the model is highly significant and in good adequacy with experimental results ${ }^{40}$.

\section{References}

1- N. Guettai, H. A. Amar, Photocatalytic oxidation of methyl orange in presence of titanium dioxide in aqueous suspension, Part I: Parametric study. Desalination, 2005, 185, 427-437.

2- R. Han, Y. Wang, W. Zou, Y. Wang, J. Shi, Comparison of linear and nonlinear analysis in estimating the Thomas model parameters for methylene blue adsorption onto natural zeolite in a fixed-bed column, J Hazard Mater, 2007, 145, 331-335.

3- G. Crini, Studies on adsorption of dyes on betacyclodextrin polymer, Bioresour Technol, 2003, 90, 193-198.

4- R. Malarvizhi, N. Sulochana, Sorption Isotherm and Kinetic Studies of Methylene Blue Uptake onto Activated Carbon Prepared from Wood Apple Shell, Journal of Environmental Protection Science, 2008, 2, 40-46.

5- V. K. Garg, M. Amita, R. Kumar, R. Gupta, Basic dye (methylene blue) removal from simulated wastewater by adsorption using Indian Rosewood sawdust: a timber industry waste, Dyes Pigments, 2004, 63, 243-250.

6- X. Zhang, T. Lu, X. Xu, Y. Wang, The fabrication of a nanoscale polyoxometalate based magnetic adsorbent and its selective adsorption of cationic dyes, J Coord Chem., 2017, 70, 60-70.

7- I. E. Ouahabi, R. Slimani, I. Hachoumi, F. Anouar, N. Taoufik, A. Elmchaouri, S. Lazar, Adsorption of a cationic dye (Yellow Basic 28) onto the calcined mussel shells: Kinetics, Isotherm and Thermodynamic Parameters, Mediterr J Chem., 2015, 4, 261-270.

8- A. K. Sharma, B. S. Kaith, N. Sharma, J. K. Bhatia, V. Tanwar, S. Panchal, S. Bajaj, others, Selective removal of cationic dyes using response surface methodology optimized gum acaciasodium alginate blended superabsorbent, Int J Biol Macromol., 2019, 124, 331-345. 
9- H. Mehr, J. Saffari, S. Mohammadi, S. Shojaei, The removal of methyl violet $2 \mathrm{~B}$ dye using palm kernel activated carbon: thermodynamic and kinetics model, Int J Environ Sci Technol., 2019, $1-10$.

10-S. Shojaei, S. Khammarnia, S. Shojaei, M. Sasani, Removal of reactive red 198 by nanoparticle zero valent iron in the presence of hydrogen peroxide, J Water Environ Nanotechnol., 2017, 2, 129-135.

11-M. Álvarez, L. Ilzarbe, E. Viles, M. Tanco, The use of genetic algorithms in response surface methodology, Qual Technol Quant Manag., 2009, 6, 295-307.

12-M. S. Chiou, H. Y. Li, Adsorption behavior of reactive dye in aqueous solution on chemically cross-linked chitosan beads, Chemosphere, 2003, 50, 1095-1105.

13-M. Özacar, I. A. Şengil, Adsorption of metal complex dyes from aqueous solutions by pine sawdust, Bioresour Technol, 2005, 96, 791-795.

14- R. Han, J. Zhang, P. Han, Y. Wang, Z. Zhao, M. Tang, Study of equilibrium, kinetic and thermodynamic parameters about methylene blue adsorption onto natural zeolite, Chem Eng J., 2009, 145, 496-504.

15-L. Shi, L. Hu, J. Zheng, M. Zhang, J. Xu, Adsorptive removal of methylene blue from aqueous solution using a Ni-metal organic framework material, J Dispers Sci Technol., 2016, 37, 1226-1231.

16-I. Lebkiri, B. Abbou, L. Kadiri, A. Ouass, Y. Essaadaoui, A. Habssaoui, E. H. Rifi, A. Lebkiri, Removal of methylene blue dye from aqueous solution using a superabsorbant hydrogel the polyacrylamide: isotherms and kinetic studies, Mediterr J Chem., 2019, 9, 337-346.

17-B. S. Kaith, U. Shanker, B. Gupta, others, Onepot green synthesis of polymeric nanocomposite: biodegradation studies and application in sorption-degradation of organic pollutants, $\mathbf{J}$ Environ Manage, 2019, 234, 345-356.

18-A. K. Sharma, B. S. Kaith, V. Tanwar, J. K. Bhatia, N. Sharma, S. Bajaj, S. Panchal, others, RSM-CCD optimized sodium alginate/gelatinbased $\mathrm{ZnS}$-nanocomposite hydrogel for the effective removal of biebrich scarlet and crystal violet dyes, Int J Biol Macromol., 2019, 129, 214-226.

19-C. Pierre, Les plans d'expériences partie 1: Principes généraux, Rev Contrôles-Essais-Mes, 2005, 69-72.

20-J. Goupy, Plans d'expériences, Ed. Techniques Ingénieur, 2006.

21-A. K. Sharma, B. S. Kaith, S. Bajaj, J. K. Bhatia, S. Panchal, N. Sharma, V. Tanwar, others, Efficient capture of eosin yellow and crystal violet with high-performance xanthan-acacia hybrid super-adsorbent optimized using response surface methodology, Colloids Surf B Biointerfaces, 2019, 175, 314-323.
22-J. Goupy, L. Creighton, Introduction aux plans d'expériences, Paris Fr, 2001.

23-K. Adinarayana, P. Ellaiah, B. Srinivasulu, R. B. Devi, G. Adinarayana, Response surface methodological approach to optimize the nutritional parameters for neomycin production by Streptomyces marinensis under solid-state fermentation, Process Biochem., 2003, 38, 1565-1572.

24-A. V. Schenone, L. O. Conte, M. Botta, O. M. Alfano, Modeling and optimization of photoFenton degradation of 2,4-D using ferrioxalate complex and response surface methodology (RSM)., J Environ Manage, 2015, 155, 177-183.

25-A. S. Bueno, C. M. Pereira, B. Menegassi, J. A. G. Arêas, I. A. Castro, Effect of extrusion on the emulsifying properties of soybean proteins and pectin mixtures modelled by response surface methodology, J Food Eng., 2009, 90, 504-510.

26-R. Baggio, D. Contreras, Y. Moreno, R. Arrue, I. Paulus, O. Peña, J.-Y. Pivan, Magnetostructural study and synthesis optimization of a phosphovanadate copper complex, $\left[\mathrm{Cu}(\mathrm{VO})_{2}\right.$ $\left.\left(\mathrm{PO}_{4}\right)_{2}\left(\mathrm{H}_{2} \mathrm{O}\right)_{4}\right]_{\mathrm{n}}$, J Coord Chem., 2012, 65, 2319-2331.

27-S. E. A. El Hassani, A. Driouich, H. Mellouk, B. Bejjany, A. Dani, K. Digua, Extraction of phenolic from Moroccan grape pomace: Optimization of decoction extraction of phenolic compounds using response surface methodology, Mediterr J Chem., 2018, 7, 423-432.

28-J. Ahmadi, M. Davoodabadi Farahani, B. Mehdizadehd, M. Pirkamali, others, Removal of crystal violet using nanozeolite-x from aqueous solution: Central composite design optimization study, J Water Environ Nanotechnol, 2019, 4, 40-47.

29-C. Bodson, Application de la technologie analytique des procédés dans l'étude de l'homogénéité de mélanges de poudres pour compression directe, 2007.

30-O. Fatima, E. K. Mhamed, T. Mohamed, A. Rachid, Adsorption of methylene blue onto artichoke waste, Orient J Chem., 2015, 31, 2037-2041.

31-S. Shojaei, Optimization of process variables by the application of response surface methodology for dye removal using nanoscale zero-valent iron, Int J Environ Sci Technol., 2019, 16, 4601-4610.

32-A. Kunamneni, K. S. Kumar, S. Singh, Response surface methodological approach to optimize the nutritional parameters for enhanced production of -amylase in solid-state fermentation by Thermomyces lanuginosus, Afr J Biotechnol., 2005, 4, 708-716.

33-M. Y. Can, Y. Kaya, O. F. Algur, Response surface optimization of the removal of nickel from aqueous solution by cone biomass of Pinus sylvestris, Bioresour Technol., 2006, 97 , 1761-1765. 
34-B. K. Körbahti, N. Aktaş, A. Tanyolaç, Optimization of electrochemical treatment of industrial paint wastewater with response surface methodology, J Hazard Mater., 2007, 148, 83-90.

35-S. Shojaei, S. Shojaei, M. Pirkamali, Application of Box-Behnken Design Approach for Removal of Acid Black 26 from Aqueous Solution Using Zeolite: Modeling, Optimization, and Study of Interactive Variables, Water Conserv Sci Eng., 2019, 4, 13-19.

36-D. Mathieu, J. Nony, R. Phan-Tan-Luu, NemrodW, version 2000, LPRAI Marseille, 2000.

37-A. K. Sharma, B. S. Kaith, S. Panchal, J. K. Bhatia, S. Bajaj, V. Tanwar, N. Sharma, others, Response surface methodology directed synthesis of luminescent nanocomposite hydrogel for trapping anionic dyes, J Environ Manage, 2019, 231, 380-390.

38-S. Shojaei, S. Shojaei, M. Sasani, The efficiency of eliminating Direct Red 81 by Zero-valent Iron nanoparticles from aqueous solutions using response surface model (RSM), Model Earth Syst Environ., 2017, 3, 27.

39-K. Ravikumar, S. Krishnan, S. Ramalingam, K. Balu, Optimization of process variables by the application of response surface methodology for dye removal using a novel adsorbent, Dyes Pigments, 2007, 72, 66-74.

40-J. Paik, S. Vogel, R. Piantedosi, A. Sykes, W. S. Blaner, K. Swisshelm, 9-cis-retinoids: biosynthesis of 9-cis-retinoic acid, Biochemistry, 2000, 39, 8073-8084. 